\title{
Study on Problems and Improvement Measures of China's Sports Intangible Cultural Heritage Protection
}

\author{
Xiaorong Chen \\ Department of P.E. \\ Shenzhen University \\ Shenzhen, China \\ sherryshao_1982@hotmail.com
}

\author{
Xueyun Shao \\ Golf College \\ Shenzhen University \\ Shenzhen, China \\ shaoxy@szu.edu.cn
}

\begin{abstract}
Based on literature and investigation, this paper points out the main problems of our country in sports intangible cultural heritage protection at present are ambiguous type of ownership, insufficient funds, defective laws \& regulations, protection of inheritance, unclear of the relationship between protection and development. Accordingly, four corresponding measures are put forward to as follows: bring sports intangible cultural heritage into school physical education curriculum system, perfect laws and regulations, intensify law efforts, increase efforts to protect inheritance, and establishment of China's intangible cultural heritage resources in sport database.
\end{abstract}

Keywords-China; sports intangible cultural heritage; protection; measure

\section{INTRODUCTION}

"The intangible cultural heritage is a kind of cultural handing down through oral teaching from generation to generation. Due to this cultural heritage is kept deeply inside the folk. It is the cultural gene of a nation's ancient life memories and a kind of active state, reflecting a nation's wisdom and spirit."[1] At present, China is the world's country which has the most quality of the world intangible cultural heritage in number, a total of 31 . The State Council of China has announced three batches of national level intangible cultural heritage items from 2006 to 2011, with a total of 1219 .

\section{STATUS OF CHINESE INTANGIBLE CULTURAL HERITAGE}

In order to strengthen the protection work of intangible cultural heritage in China, the State Council of China issued the Opinions of the State Council on strengthening the protection of intangible cultural heritage in China in 2005. The Ministry of culture in 2006 December released the Interim measures of national level intangible cultural heritage protection and management regulations. According to the regulation, the national intangible cultural heritage refers to all intangible cultural heritage projects which included in the name list approved by the State Council. It also specified the guidelines, principles, responsibility of the protection work. Law of the People's Republic of China on Intangible Cultural Heritage was adopted on February, 2011, and implemented from June 1, 2011. It provides provisions and requirements from the height of legal on the related work of intangible cultural heritage, showing how import that the nation regards it, also makes the work has laws to go by.

Therefore, a widespread attention has been paid from local to national to the protection of the intangible cultural heritage. However, compared to countries such as Japan and Britain, the legal provisions in China developed much more lately. There are still many work need to be perfection. In terms of legal policy, it must really let the legal provisions to encourage right protection behavior, and restricts behavior of damage or potential damage to the intangible cultural heritage.

Based on comprehensive analysis, there are several mainly problems existed in our countries' protection work of intangible cultural heritage at present. With respect to policy implementation of intangible cultural heritage, main problems includes: taking heritage declaration seriously, looking down on its protection; contempt to industrialization development to replace the protection; heritage privately; fraud of heritage and inheritance; heritage protection subject and object dislocation; selective protection etc.. As far as inheritance of intangible cultural heritage concerned, issues exist mainly as follows: the aging of inheritance; single way of inheritance; lack of the main transmission body; not enough popularity promotion; over long and difficult of practicing cycle; not optimistic transmission environment. The main problems in the protection of the intellectual property law include: single protection model; ignored rights and responsibility of related subjects; unknown legal liability; lack of effective encourage and supervision mechanism; universal phenomenon of inappropriate use.

To sum up, the main problems of our country in intangible cultural heritage protection at present are: the aging of inheritance; not sound laws and regulations; lack of funds; single way of protection; uncertainty of protection and exploitation degree.

\section{Status OF Chinese SpORTS InTANGIBLE CUlTURAL HERITAGE PROTECTION}

Sports are an important part of China's traditional culture. Chinese folk-custom sports, folk sports and national sports not only have various forms activities, but also rich in culture, having an important impact on people's production and daily life for thousands of years. There are a total of 58 excellent traditional sports included in three batch of national 
intangible cultural heritage list announced by the State Council from 2006 to 2011, such as Shaolin Kungfu, Taijiquan, Cuju, Hua Tuo Wuqinxi. Besides this, according to initial statistics, China has more than 800 items of sports intangible cultural heritage, adding some sports items included in the traditional dance and folk-custom, and the province/municipality level intangible cultural heritage directory released by each provinces \& municipality directly under the Central Government, not including the municipal and county - level intangible cultural heritage items.

The State General Administration of sports points out in opinions about strengthen sports cultural construction that mining and protection of sports cultural heritage should be strengthened in 2011. It also indicated that qualified area should actively promote declaration of sports intangible cultural heritage. Collection, collation, preservation and utilization work of sports cultural relics, archives, sports literature should be paid attention to and carried out.

However, with the development of globalization, the rapid development of economy, the rapid social change, the intrusion of cultural hegemony and the influence of current urbanization transformation implementation factors, China's sports intangible cultural heritage is facing the grim situation of accelerated demise. The unique characteristics of sports intangible cultural heritage, such as intangible, perishable and oral teaching, format this situation as well.

Besides the common characteristics of intangible cultural heritage protection work, there are special problems in our country's sports protection of intangible cultural heritage. The following shows main research problems existed in the workplace of sports intangible cultural heritage protection at present.

\section{A. Type of Ownership}

China's sports intangible cultural heritage has problems on type of ownership, just like unclear category, indistinct concept definition and disunion use of name. Traditional sports items belong to acrobatics in the first batch of national list in 2006; and to acrobatics \& sports in second \& third batch of list and the expand directory in 2008 and 2011. From the classified name change, it can be seen that the state gradually improved awareness and conservation efforts towards sports intangible cultural heritage, nevertheless, the definition of the concept of sports intangible cultural heritage has yet been in suspense. Sports intangible cultural heritage includes national sports, folk-custom sports and folk sports, which combine multiple functions of entertainment, season's celebration, religious worship and fitness together. It shows that it is very hard to define sports intangible cultural heritage. Is it athletics, acrobatics, traditional dances or folkcustom activity? The uncertainty concept and classification makes overflow using of all kinds of names but not unified, leading to confusion and uncertainty, causing a lot of inconvenience for researchers.
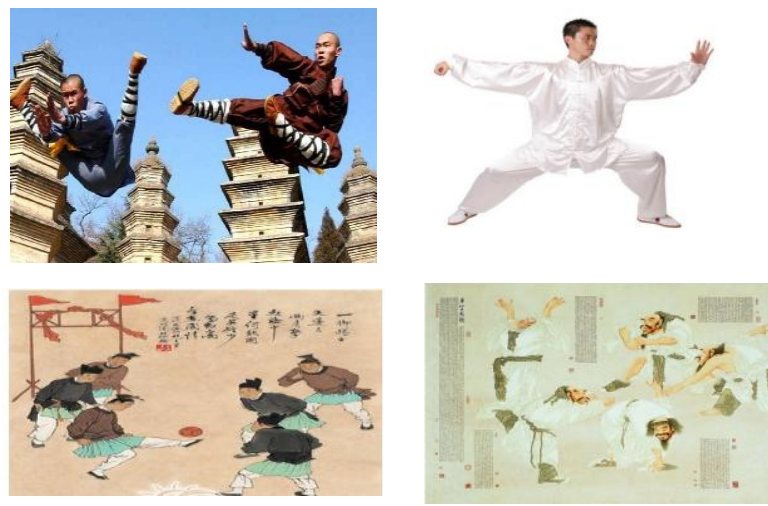

Figure 1.Example of Chinese sports intangible cultural heritage items

Therefore, the most pressing demand of the day of our sports intangible cultural heritage research is to divide the national traditional sports intangible cultural heritage protection list scientifically, define sports intangible cultural heritage concept clearly, straighten out the relationship between related concepts of sports intangible cultural heritage, traditional sports, folk-custom sports activities.

\section{B. Insufficient Funds}

Lack of funds hinders the smooth protection work of China's development of intangible cultural heritage, which mainly reflected in two aspects. First is the shortage of investigation and census funds. Sports intangible cultural heritage census work involves a wide range and large workload, needing a lot of manpower support. Due to insufficient funds, it is difficult to guarantee the truthiness of research data and the integrity of the census work when carrying out large-scale research work. Second limits many experts and scholars do related research work because of not enough funding, affecting their enthusiasm. These factors directly affect the reliability of the census data and the continuity of the protection work. The limited funds made many valuable items cannot be further investigated. Third are not enough funds to meet the living needs of inheritance. Inadequate protection and rescue funds affect carrying out normal protection activities, such as granting inheritance's allowance. It follows that, sufficient money or not, not only affects the census work breadth and depth, but also determines the census form and census data storage method.

\section{Defective Laws \& Regulations}

The equations are an exception to the prescribed specifications of this template. You will need to determine whether or not your equation should be typed using either the Times New Roman or the Symbol font (please no other font). To create multileveled equations, it may be necessary to treat the equation as a graphic and insert it into the text after your paper is styled.

The legislation of China's protection of sports intangible cultural heritage is scattered, and lack of special law to support it, that is to say that lawlessness phenomenon is widespread[2]. A complete system of laws and regulations has not yet formed till now. So far, China has not yet had 
laws and regulations effectively protect national traditional sports intangible. Only in the Sports Law of the People's Republic of China simply mentions that "state encourages, supports excavation, consolidation and improvement of folk, folk traditional sports items". However, those 20 words is still far from enough to satisfy the protection work of rich traditional sports intangible cultural heritage which formed in five thousand years.

\section{Protection of Inheritance}

Inheritance is the successor and initiator of sports intangible cultural heritage their understanding of their own skills and teaching ability directly affect the quantity of sports intangible cultural heritage and the quality of the audience[3]. At present, problems faced in our country's sports intangible cultural heritage inheritance are too few in number but aging, and fault of them etc.. Young people are not interested in learning the traditional skills, and not willing to inherit the culture. All mentioned above results in a lot of sports intangible cultural heritage is not timely rescued and protected, leading to the danger of extinction.

\section{E. Unclear of the Relationship between Protection and Development}

Sports intangible cultural heritage has certain features like ornamental and entertainment, so it has certain economic value, which drives the development of tourist industry and entertainment industry. But because of this, some local governments over pursuit of its economic benefits while downplay the cultural values, ignoring the inheritance and promotion of cultural connotation, which are also the common problems existed in sports intangible cultural heritage protection work. The local government has two hot two cold phenomenon in the protection process, i.e., taking been reported seriously but despising census, and also thinking highly of benefit but setting down of protection. The local government should correctly understand and treat the relationship between protection and development, attaching more importance to protection of the rich foundation of sports intangible cultural heritage. The essence of the culture should be kept at the same time, while in use of sports intangible cultural heritage for the legitimate interests.

\section{PROTECTION MEASURES OF SPORTS INTANGIBLE CULTURAL HERITAGE IN CHINA}

\section{A. Bring into School Physical Education Curriculum System}

The sports intangible cultural heritage protection items should be considered as local curriculum and school-based curriculum school protecting regions physical education in school, bringing it into universities, middle and primary schools physical education class. Sports intangible cultural heritage items skills and culture are taught to students by utilizing physical education. Students not only can get skills of national traditional fitness and regimen, but also improve their understanding of national history and culture. What's more, the students' awareness of the protection of traditional culture would be strengthened, and their ethnic pride and sense of identity would be promoted. Eventually, students will truly experience the charm of Chinese traditional sports culture, deepen and reproduce national memory. In a word, it is a feasible and recommendation form to promote and inherit traditional sports culture through school physical education.

\section{B. Perfect Laws and Regulations, Intensify Law Efforts}

In front of the predicament of imperfect legal system, the sports intangible cultural heritage protection legislation should adhere to the principle of people-oriented, government leading and integrity. Legal protection pattern mainly has public law protection, private law protection and the combination of public law \& private law mode. The construction of supporting legislation of sports law should be speeded up. Legal subject and responsibility of national tradition sports intangible cultural heritage should be clear. Affirmation of traditional ethnic sports intangible cultural heritage should be standardized.

\section{Increase Efforts to Protect Inheritance}

The orally teaching of sports intangible cultural heritage make the protection of inheritance becomes a very important problem. The government needs to enlarge the intensity of investment of determination, development and protection of inheritance. It has to emphasize the construction of inheritance team building to build a reasonable and effective one. Especially in local sports colleges and universities, a large input should be thrown to national traditional sports major. It should focus on developing staff and coaches, athletes and other senior specialized talents with a higher level of professional quality and professional skills of sports intangible cultural heritage protection, so that sports intangible cultural heritage will be promoted from local to nation, and finally to the world, becoming one of people's beloved sport from different nationalities, different countries, different languages and different cultural background.

\section{Establishment of China's Intangible Cultural Heritage Resources in Sport Database}

With the rapid development of computer network technology, mankind has entered the information society, and the way of people getting information has changed tremendously. Because of its unique advantages in the preservation and dissemination, digital technology has been widely used in cultural heritage preservation and display, becoming an important channel for the protection of intangible cultural heritage. The general office of the State Council clearly pointed out in Opinions about strengthen China's intangible cultural heritage protection work that "it must have the means and methods of modern communication no matter in protection, rescue, or use of inheritance and development." It also shows that intangible cultural heritage should be recorded really, systematically and comprehensively and create file and database using various ways of wording, sound recording, video, digital multimedia and etc..

Digital resources database has obvious advantage in resource exchange, resource sharing, resource management 
and so on. Technology method for digital protection method has characteristics of diversity ways, timely protection, widely spread, scientific and accurate management. It can provide strong technical support in protection, transmission, dissemination and development for intangible cultural heritage. It is evident that one of the best ways for the protection and inheritance of the intangible cultural heritage is to establish a database.

In brief, using of the most advanced digital technology to protect ancient intangible cultural heritage is an important means and development trend of world cultural heritage protection and heritage. Construction of resource database is not only a tool for protecting sports intangible cultural heritage, but also provides a broad space for the display and dissemination of sports intangible cultural heritage resources.

\section{CONCLUSION}

Besides the common characteristics of intangible cultural heritage protection work, there are special problems in our country's sports protection of intangible cultural heritage. Although four corresponding measures are put forward to in this paper, in order to make the results more close to the actual application, future studies should focus on analyzing and researching on the impact of various factors of intangible cultural heritage protection, based on its overall features. By doing this, the level of intangible cultural heritage protection work can be effectively improved.

\section{ACKNOWLEDGMENT}

This paper is financially supported by General Project of Pedagogy Eleven Five Planning 2010 (Grant No. BLA100104), National Social Science Foundation of China (Grant No. 13CTY034), and Foundation for Distinguished Young Talents in Higher Education of Guangdong, China (Grant No. 2012WYM_0117).

Corresponding Author

Xueyun Shao, shaoxy@szu.edu.cn, 86+13510198798.

\section{REFERENCES}

[1] W.Z. Wang, Overview of intangible cultural heritage. Culture and Art Press. 2010.10

[2] Z. Wang, "Study on legislation of traditional sports intangible cultural heritage protection in China," Journal of Beijing Sport University, 2011,04.

[3] Y Liu, "On the path of sports intangible cultural heritage protection," Beijing Sport University, 2012. 